
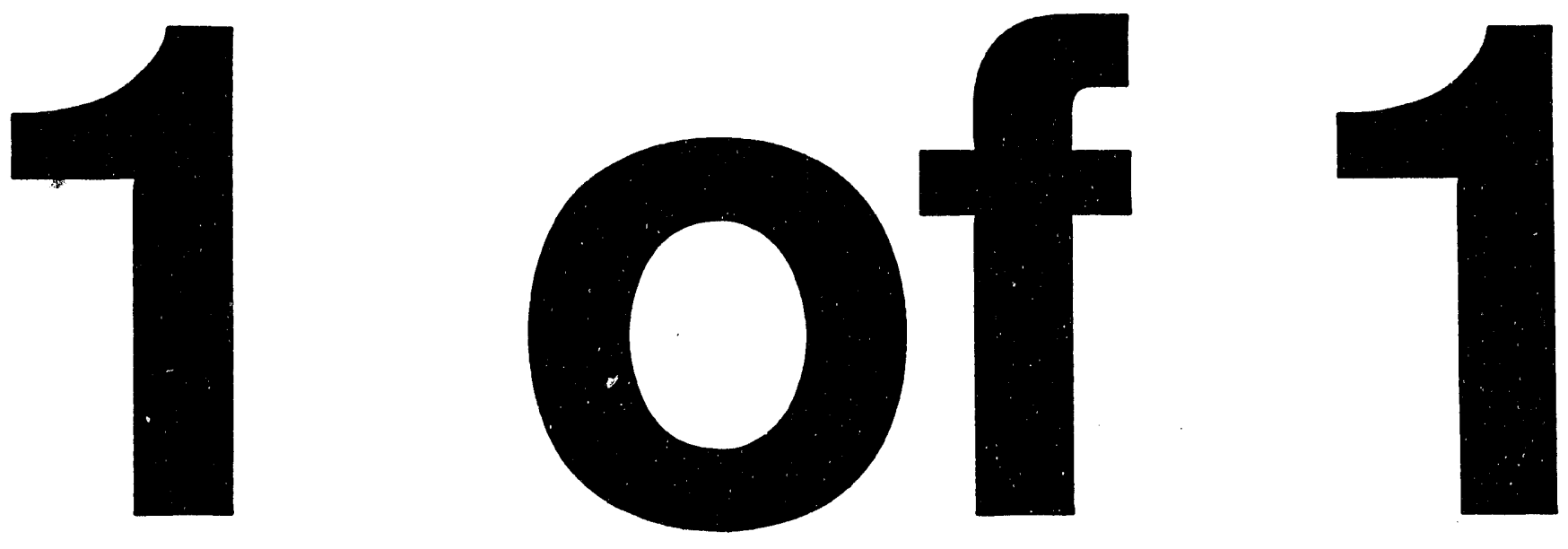
PNL-SA-24303

\section{CALCULATION OF ATOM-CENTERED PARTIAL CHARGES FOR HEME}

\section{DISCLAIMER}

\author{
J. I. Manchester \\ M. D. Paulsen \\ R. L. Ornstein
}

May 1994

\begin{abstract}
This report was prepared as an account of work sponsored by an agency of the United States Government. Neither the United States Government nor any agency thereof, nor any of their employees, makes any warranty, express or implied, or assumes any legal liability or responsibility for the accuracy, completeness, or usefulness of any information, apparatus, product, or process disclosed, or represents that its use would not infringe privately owned rights. Reference herein to any specific commercial product, process, or service by trade name, trademark, manufacturer, or otherwise does not necessarily constitute or imply its endorsement, recommendation, or favoring by the United States Government or any agency thereof. The views and opinions of authors expressed herein do not necessarily state or reflect those of the United States Government or any agency thereof.
\end{abstract}

Presented at the

27th Jerusalem Symposium in Quantum

Chemistry and Biochemistry

May 23-26, 1994

Jerusalem, Israel

Prepared for

the U.S. Department of Energy

under Contract DE-AC06-76RLO 1830

Pacific Northwest Laboratory

Richland, Washington 99352 


\title{
Calculation of Atom-Centered Partial Charges for Heme
}

\author{
JOHN I. MANCHESTER, MARK D. PAULSEN and RICK L. ORNSTEIN \\ Molecular Science Research Center, Pacific Northwest Laboratory, Richland, WA 99352
}

\begin{abstract}
Atom-centered partial charges are calculated for the Fe-heme in cytochrome P450cam for use in molecular dynamics simulations of polar substrates bound in the active site of the enzyme. Charges are fit to the electrostatic potential produced by ab initio UHF wavefunctions for an Fe-porphine model. Basis set dependence of these charges is observed using the LANL1DZ, LANL2DZ and augmented 6-31G levels of theory. Upon geometry optimization of the enzyme, these charge sets cause varying degrees of distortion of the porphyrin from its crystallographically observed conformation. Scaling the charges calculated from the augmented $6-31 \mathrm{G}$ basis by $75 \%$ reduces the heme distortion while preserving reasonable interactions with a polar substrate. A comparison of the calculated charges with other published values is presented.
\end{abstract}

\section{Introduction}

Cytochromes $\mathrm{P} 450$ are a class of hemeproteins that catalyze a variety of oxygenation reactions by activating molecular oxygen and inserting it into organic compounds such as hormones and xenobiotics. In an anaerobic environment, these enzymes are also capable of reductively dehalogenating heavily halugenated hydrocarbons, ${ }^{1.2}$ commonly used in organic synthesis and as solvents. The ability of P450s to catabolize these compounds has attracted attention to the possibility of using reconstituted systems, or genetically engineered organisms, to degrade halohydrocarbons that now constitute a major contaminant class at industrial waste sites. Wackett and coworkers ${ }^{3}$ observed significant rates for dechlorination of hexachloroethane using a purified P450cam system, but observed no dechlorination of 1,1,1-trichloroethane (TCE). In a recent MD simulation of the wild-type enzyme with TCE bound in the active site, ${ }^{4}$ we observed that the substrate populated an unreactive conformation for the duration of production dynamics--a result in qualitative agreement with the experimental observation that TCE is not catabolized by P450cam.

An examination of the components of the enzyme-substrate intermolecular energies in the MD simulations indicated that is was electrostatic repulsion between the heme group and TCE which dominated enzyme-substrate interactions and determined the observed substrate orientation. Although the results of this $\mathrm{MD}$ simulation are in qualitative agreement with experiment, a comparison of the partial charges used on the heme cofactor with those used by others in simulations of hemeproteins suggests that the charge set we used may have exaggerated the heme-TCE repulsion. In many ways the parameterization of atomcentered partial charges is the most difficult and subjective part of any empirical forcefield. Recently, however, electrostatic potential derived (PD) charges have gained widespread acceptance for use in molecular mechanics calculations. We applied this approach to reparameterize the charges used in our $\mathrm{MD}$ simulations, which implement the consistentvalence forcefield. ${ }^{5}$ In this paper we assess the effect of basis set on the PD charges for a model of the heme cofactor and evaluate the charge sets for the effect on substrate-enzyme interaction energies and on equilibrium heme geometry. A comparison with other published charge sets for the heme cofactor is also presented. 


\section{Methods}

$A b$ initio calculations were performed using Gaussian $92^{6}$ on a model of the heme prosthetic group in cytochrome P450, shown in Figure 1. All substituents are removed from the heme, leaving an Fe-porphine, and the cysteine axial ligand is truncated to methyl mercaptide. Unique bond lengths and bond angles are indicated on the diagram; they were obtained by assuming four-fold symmetry and averaging the corresponding geometrical parameters from the crystal structure of camphor-bound P450cam.7 The porphine model used was constrained to planarity, except for $\mathrm{Fe}(0.45 \AA$ below the plane) and its axial ligand. The $\mathrm{Fe}$ was modeled as a +3 ion in a high-spin state $(\mathrm{S}=5 / 2)$, the experimentally observed state for the binary complex of P450cam and a variety of substrates and substrate analogs. Unrestricted Hartree-Fock (UHF) calculations were performed on this system without geometry optimization, using three basis sets: LANL2DZ, LANL1DZ and an augmented 6-31G basis. The LANL2DZ"1 basis set consists of the standard 3-21G basis for all first- and second-row atoms, together with Hay and Wadt's" (341/311/41) valence contraction for $\mathrm{Fe}$. The $1 \mathrm{~s}, 2 \mathrm{~s}$ and $2 \mathrm{p}$ orbitals of $\mathrm{Fe}$ are represented by an effective core potential. LANL1DZ"1 consists of Dunning's double-zeta basis set ${ }^{12}$ on first- and secondrow elements, with the (21/11/41) valence contraction. The final basis set we used consists of the 6-31G basis for first- and second-row elements (polarization functions were used on all heavy atoms with the addition of diffuse functions on Fe ligands) with Wachter's ${ }^{13}$ allelectron contraction (62111111/3312/32) on Fe. Singie-point SCF convergence criteria were imposed. PD-charges were calculated using Breneman's CHELPG algorithm ${ }^{8}$ as implemented in Gaussian 92. CHELPG employs a grid method to select points at which the electrostatic potential of the molecule is sampled. The method has the advantage that the resulting charges are relatively insensitive to internal bond rotations and the orientation of the molecule in space. Other methods9.10 demonstrate some sensitivity to these properties. 8 Fe was assigned a van der Waals radius of $1.95 \AA$. For all other atoms the default atomic radii were used, and the fitting procedure was constrained to reproduce the total charge of the molecule.

Molecular mechanics interaction energies (van der Waals and Coulomb components) between the substrate and the heme cofactor were calculated using the Discover simulation package (Biosym Technologies v2.9). TCE was docked into the active site of P450cam by positioning the substituted carbon of TCE at the coordinates of atom C5 of the camphor molecule in the P450cam crystal structure. Camphor is hydroxylated at the $\mathrm{C5}$ position by the wild-type enzyme. Charges on TCE had previously been calculated with CHELPG on a geometry fully optimized at 6-31G*. A few steps of geometry optimization were performed on the complex so that the substrate relaxed to nonbonded contact with the heme- $\mathrm{Fe}$ and (in some cases) the pyrrole nitrogens. Only the porphine model of the heme cofactor and the substrate were included in these calculations.

To assess the influence of various charge sets on the equilibrium geometry of the heme, the calculated PD-charges from different wavefunctions were assigned to the atoms of the porphine core, while charge balance (to a total of -2 ) was maintained on the entire porphyrin by adjusting charges on the sidechains in small increments. One thousand steps of conjugate gradients minimization were performed on the crystal structure of camphorbound cytochrome P450cam, including the crystallographic waters, using an all-hydrogen model and the consistent-valence forcefield. ${ }^{5}$ The entire enzyme was free to move during minimization. Nonbonded interactions were evaluated using a group-based switching function between 12.0 and $15.0 \AA$, and the nonbonded pair list was updated at each minimization step.

Heme Partial Charges, Page 2 


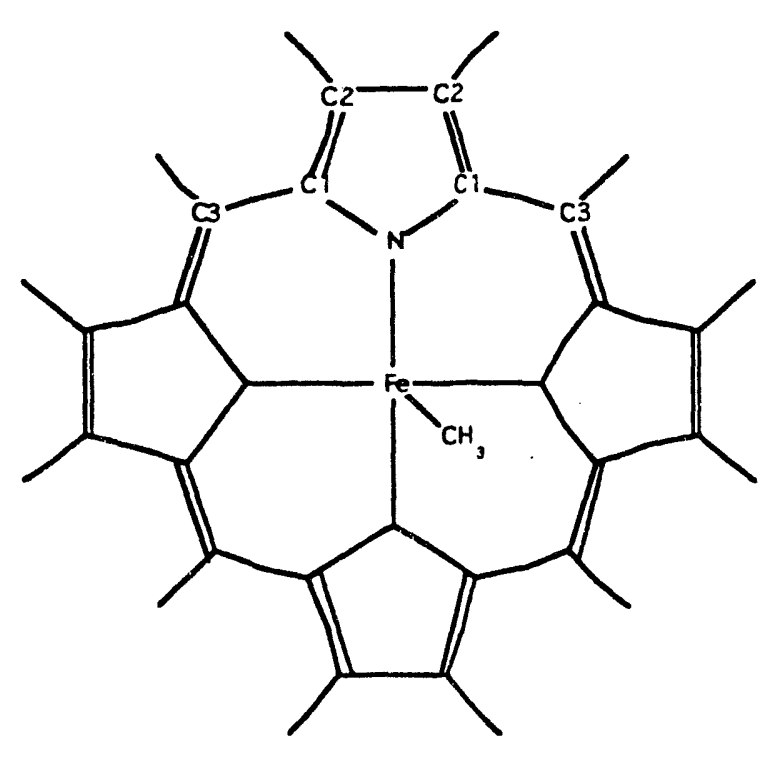

$\begin{array}{ll}\text { Geometrical Parameters } \\ \mathrm{Fe}-\mathrm{N} & 2.05 \\ \mathrm{~N}-\mathrm{C} 1 & 1.38 \\ \mathrm{C} 1-\mathrm{C} 2 & 1.45 \\ \mathrm{C} 2-\mathrm{C} 2 & 1.46 \\ \mathrm{C} 2-\mathrm{C} 3 & 1.45 \\ \mathrm{C}-\mathrm{H} & 1.09 \\ \mathrm{C} 1-\mathrm{N}-\mathrm{C} & 110.0 \\ \mathrm{~N}-\mathrm{C} 1-\mathrm{C} & 109.0 \\ \mathrm{C} 1-\mathrm{C} 2-\mathrm{C} 3 & 106.0\end{array}$

Figure 1. $A b$ initio calculations were performed on this planar heme model. Geometrical parameters were obtained assuming four-fold symmetry and averaging internal coordinates in the crystal structure of camphor-bound $\mathrm{P} 450 \mathrm{cam}^{7}$. Heme sidechains were replaced with $\mathrm{H}$ atoms, and $\mathrm{Fe}$ lies $0.45 \AA$ out of the heme plane. All bond lengths shown are in Angstroms, and bond angles are in degrees. Note that view on left is along $\mathrm{Fe}-\mathrm{S}$ bond.

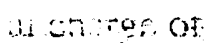

\section{Results and Discussion}

To determine the sensitivity of electrostatic potential-derived (PD) charges to the basis set used in $a b$ initio calculations on the heme, we performed UHF single-point calculations using three different basis sets. The resulting charges are shown in Table I. The larger magnitudes of the charges calculated from LANL1DZ relative to LANL2DZ, especially on $\mathrm{Fe}$ and its ligands, indicate that the Fe-ligand interactions are more ionic than covalent in nature. This result is in part due to freezing the $3 \mathrm{~s}$ and $3 \mathrm{p}$ electrons in the calculation. Although LANL2DZ consists of a larger basis for Fe, the standard 3-2G basis is used for first- and second-row atoms. In an attempt to achieve a more balanced basis set, we chose Wachter's all-electron double-zeta quality basis for $\mathrm{Fe},{ }^{13}$ and an augmented $6-31 \mathrm{G}$ basis set for the remaining atoms in the heme. In fitting PD charges for small organic molecules, the 6-31G* basis set is commonly used. 14 The augmented $6-31 \mathrm{G}$ basis produced small changes in the partial charges compared to the LANL2DZ basis set, with the exception of charges on $\mathrm{Fe}$ and $\mathrm{C} 3$ atoms (see Fig. 1). 


\begin{tabular}{lcccccc}
\hline & Fe & S & N & C1 & C2 & C 3 \\
\hline CVFF & 1.22 & 0.10 & -0.55 & 0.05 & -0.10 & -0.10 \\
6-31+G* & 1.50 & -0.24 & -0.84 & 0.58 & -0.28 & -0.64 \\
LANL1DZ & 1.94 & -1.04 & -1.25 & 0.98 & -0.35 & -0.86 \\
LANL2DZ & 1.02 & -0.34 & -0.86 & 0.62 & -0.20 & -0.46 \\
LANL1MB $^{16}$ & 1.39 & -0.91 & -0.38 & 0.10 & -0.10 & -0.10 \\
IEHT $^{18}$ & 0.20 & -0.47 & -0.18 & 0.03 & -0.01 & 0.04 \\
INDO/S $^{22}$ & 1.50 & -0.65 & -0.40 & 0.15 & 0.15 & 0.15
\end{tabular}

Table I. Atom-centered partial charges on the heme from various sources (atoms labeled as in Fig. 1). See text for a description of calculations. CVFF denotes the charge set previously used in conjunction with Hagler's ${ }^{5}$ consistent-valence forcefield in simulations on cytochrome P450.

One limitation in treating this open-shell system with UHF is that spin contamination can arise due to the mixing of states of higher multiplicity. The value of $S^{2}$ for the pure highspin state is 8.75; LANL2DZ, LANL1DZ and the augmented 6-31G calculations converged with $S^{2}$ values of $8.754,8.927$ and 10.775 , respectively. It is at present not understood what effect spin contamination has on PD-charges. In an attempt to address this question, we also performed several ROHF calculations, which constrained $S^{2}$ to the proper value. The Gaussian 92 implementation of CHELPG gave inaccurate results for charges fit to the ROHF wavefunctions (results not shown). The source of this discrepancy is still under investigation.

Others have used a variety of quantum mechanical methods to determine iron-heme partial charges for use in molecular mechanics forcefields. Three of these charge sets, developed for use in conjunction with the Amber potential function, ${ }^{15}$ are also summarized in Table I. Most recently, Jones et al. ${ }^{16}$ used natural bond order analysis ${ }^{17}$ on an ab initio wavefunction calculated with the LANL1MB ${ }^{11}$ basis set, which includes Hay and Wadt's effective core (through $3 p$ ) on $\mathrm{Fe}$ and the minimal STO-3G basis on first- and second-row elements. The authors addressed the binding of different enantiomers of nicotine to the resting state of $\mathrm{P} 450 \mathrm{cam}$, the high-spin $\mathrm{Fe}$ (III) heme that is also under investigation in the present study. Lopez and Kollman ${ }^{18}$ parameterized the Fe (II) heme in hemoglobin and myoglobin using iterative extended Hückel (IEHT) calculations. There is some ambiguity in directly comparing this charge set with those developed for P450 since the two hemes have different axial ligands (histidine versus cysteine for P450) and different oxidation states. In addition, the magnitudes of these charges are not well matched to the other potential types of the consistent-valence forcefield; they are up to an order of magnitude smaller than charges on roughly analogous atoms in the forcefield. For example, in the consistent-valence forcefield, a pyrrole $\mathrm{N}$ has a charge of -0.56 , and a typical aromatic carbon has a charge of between -0.10 and -0.15 . Karplus and coworkers ${ }^{19}$ used a similar IEHT approach ${ }^{20}$ in developing parameters for $\mathrm{MD}$ simulations on myoglobin using CHARMM. ${ }^{21}$ Finally, Loew and coworkers ${ }^{22}$ conducted molecular dynamics simulations of valproic acid-bound cytochrome P450cam, using charges obtained from INDO/S studies on Fe-porphyrin compounds. ${ }^{23}$

To qualitatively assess the effects of these different charge sets on interactions between the heme and a polar substrate, we calculated classical interaction energies between the $\mathrm{Fe}$ porphine model in Fig. 1 and TCE by substituting each of the charge sets into the consistent-valence forcefield. A reactive conformation of the substrate is one in which a $\mathrm{Cl}$ atom of TCE is in contact with Fe; an unreactive conformation has a $\mathrm{H}$ contacting Fe. The difference in these interaction energies is a measure of each charge set's preference for the 
reactive or unreactive conformation of the substrate. This preference is plotted in Figure 2. The LANL1MB ${ }^{16}$ an IEHT ${ }^{18}$ charge sets yield preferences for the unreactive substrate conformation that are similar to those calculated with our PD-charges. However, the CVFF charge set gives a significantly larger preference for the unreactive conformation, while the INDO/S set decidedly prefers a reactive substrate conformation.

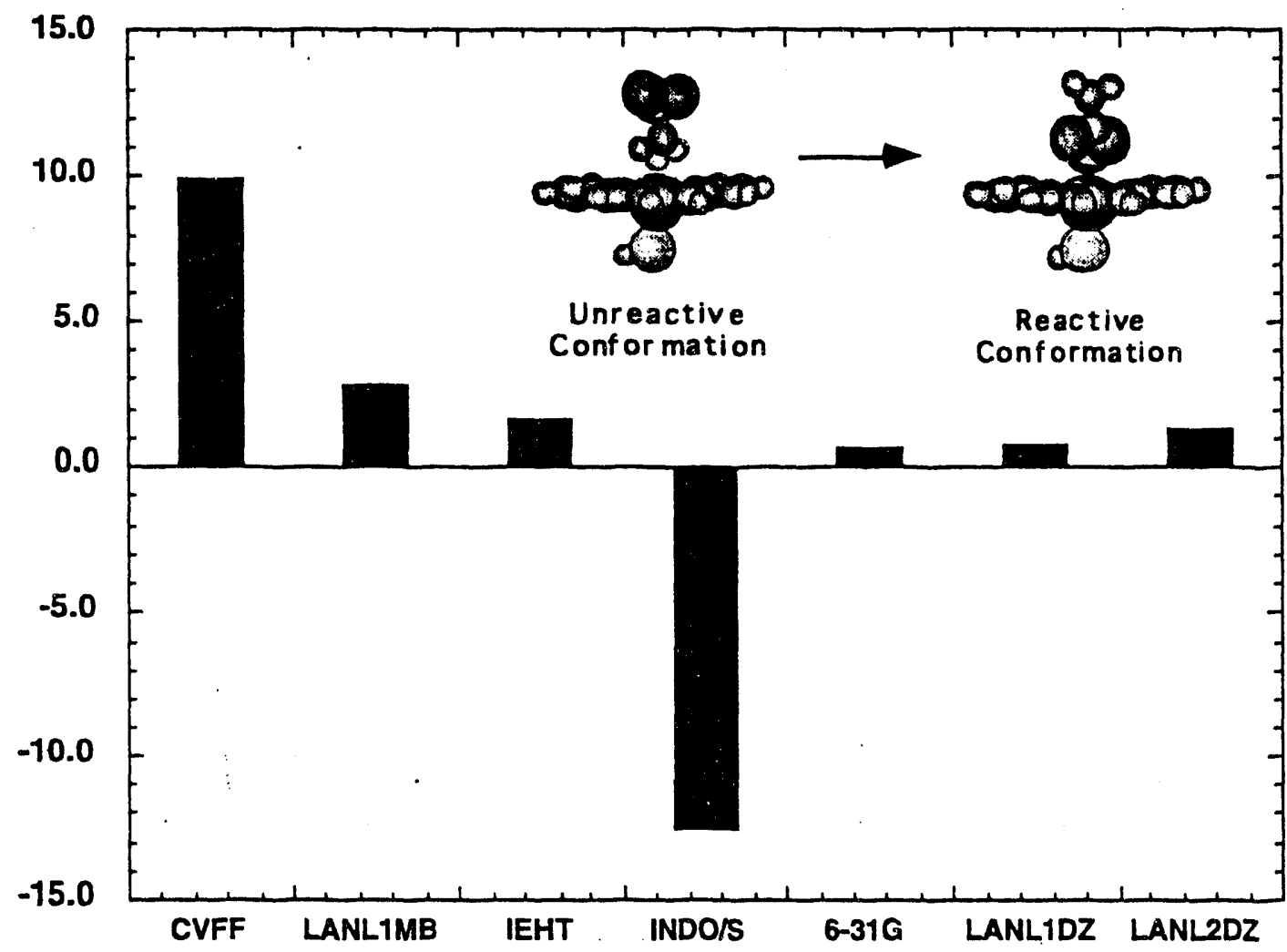

Figure 2. The preference for 1,1,1-trichloroethane to occupy a reactive conformation (with the chlorine atoms facing $\mathrm{Fe}$ ) is the difference between the interaction energy in the unreactive ard reactive conformations. The CVFF charges overestimate the preference for the unreactive conformation, while the INDO/S 22 charges overestimate the preference for the reactive conformation relative to other charge sets examined.

The INDO/S charge set is alone in placing positive charges on all $\mathrm{C} 2$ and $\mathrm{C} 3$ atoms, while the CVFF is the only set in which $S$ is positively charged. Both the CVFF charges and the INDO/S charges have been used successfully in studies of camphor, camphor analogs and other nonpolar organic molecules bound in the active site of P450cam. 22.24.25-26 However, TCE and other heavily halogenated compounds can have substantial dipole moments, which will make their interactions more sensitive to the partial charges used to represent the heme group.

In addition to correctly predicting the relative energetics of substrate-heme interactions, it is important for the partial charge set to be balanced with the bonded terms in the molecular mechanics forcefield so that the geometry of the minimized heme group is close to that determined experimentally. We determined the rms deviation in atomic position of the heavy atoms in the porphine core relative to the crystal structure of the heme group in P450cam for each of the PD-charge sets calculated. For LANL2DZ, LANL1DZ and the augmented 6-31G basis sets, respectively, these values are $0.179,0.585$ and 0.190 (see Table II). Charges from LANL1DZ produce large distortions of the heme upon 
minimization in the environment of the enzyme. Although the charges from LANL2DZ produce a slightly smaller distortion than the augmented $6-31 \mathrm{G}$ basis, the latter is a more complete basis and likely provides a more accurate description of the electron distribution in the heme.

The primary distortions that occur upon minimization of the heme with different charge sets are displacement of $\mathrm{Fe}$ toward the heme plane and an overall buckling of the porphyrin due to electrostatic attraction between the $\mathrm{C} 3$ atoms and Fe. Scaling these charges by a constant factor reduces the magnitudes of these 1,4-interactions, but it also diminishes Coulombic interactions with TCE, which are important for accurately modeling heme-substrate dynamics. Table II shows the rms deviation vetween the crystal structure and the structure minimized with 6-31G charges that were scaled by $75 \%, 50 \%$ and $25 \%$. These calculations were also performed on a neutral heme to provide a baseline, in which only van der Waals energies are present. Cutting the 6-31G charges by half reduces the distortions upon minimization to an acceptable value; these charges are also more more closely matched to the magnitudes of charges on analogous atoms in the consistent-valence forcefield. However, the preference for the unreactive conformation is also substantially reduced by this charge set. As a compromise between deviation from the crystal structure and preference for the unreactive conformation, 6-31G charges scaled by $75 \%$ are currently being used in simulations of TCE-bound P450cam.

\begin{tabular}{lcc}
\hline \multicolumn{1}{c}{ Charge Set } & $\begin{array}{c}\text { RMS Deviation from } \\
\text { Crystal Structure }\left(\AA^{\mathbf{2}}\right)\end{array}$ & $\begin{array}{c}\text { Preference for Reactive } \\
\text { Conformation }(\mathbf{k c a l} / \mathbf{m o l})\end{array}$ \\
\hline CVFF & 0.136 & 9.923 \\
LANL2DZ & 0.179 & 1.338 \\
LANL1DZ & 0.585 & 0.723 \\
6-31G & 0.190 & 0.699 \\
$\mathbf{7 5 \% ~ 6 - 3 1 G ~}$ & 0.167 & 0.104 \\
$\mathbf{5 0 \% ~ 6 - 3 1 G ~}$ & 0.108 & 0.042 \\
$\mathbf{2 5 \% ~ 6 - 3 1 G ~}$ & 0.119 & -0.299 \\
Neutral & 0.125 & -0.523 \\
\hline
\end{tabular}

Table II. Nonbonded (Coulombic) interactions within the heme can cause it to distort from the equilibrium geometry, leading to artifacts in the MD simulation. Charges calculated with the augmented 6$31 \mathrm{G}$ basis set were scaled and assigned to the heme in the crystal structure of camphor-bound cytochrome P450cam, which was subjected to 1000 steps of energy minimization. The rms values correspond to the deviation of the porphine "core" atoms of the heme in the minimized structure relative to the crystal structure. Preference for a reactive conformation is calculated as in Figure 2.

Both the size and low-lying degeneracy of states in the open-shell iron-porphyrin present a substantial challenge to obtaining an accurate quantum mechanical description of the system. Improvements in algorithms and computational resources, however, have helped to unravel these complexities. Yamamoto and Kashiwagi ${ }^{27}$ conducted $a b$ initio RHF calculations on a model for peroxidase compound II, an iron-porphine with oxygen and histidine as axial ligands. The authors also performed complete active space (CAS) SCF calculations and demonstrated the importance of including electron correlation in the porphyrin wavefunction, and later extended these calculations with an enhanced basis set. 28 Harris and Loew ${ }^{29}$ recently used a restricted open shell (ROHF/CI) extension of the INDO/S semiempirical method, to establish a mechanistic link between spin state and the observed spectra of the heme in P450cam. The INDO/S ROHF/CI method makes provisions for the effects of electron correlation using a limited configuration interaction 
approach. The present study constitutes an effort to provide a realistic model of the charge distribution for the resting state heme in P450cam. Future studies are directed at characterizing the electronic properties of the resting and intermediate states of the heme in cytochrome $\mathrm{P} 450$ with more rigorous methodology.

Acknowledgments. The authors express gratitude to Dave Feller, Thom Dunning, Jr., Sotiris Xantheas, Mark Thompson, Rick Kendall, Jeff Hay, Jeff Jones and Arka Mukherjee for valuable discussions. Special thanks to Eric Glendening and Professor Robert Rein for numerous consultations and input. Pacific Northwest Laboratory is a multiprogram national laboratory, operated for the U.S. Department of Energy by Battelle Memorial Institute under Contract DE-AC06-76RLO 1830. John Manchester has a graduate student appointee (in the Dept. of Biophysics, Roswell Park Division, State University of New York at Buffalo) administered by Associated Western Universities, in affiliation with Washington State University. This work was supported by a grant (KP0402) from the Health Effects and Life Sciences Research Division within the Office of Health and Environmental Research of the Office of Energy Research of the U.S. Department of Energy (RLO).

\section{References}

1. T.L. MacDonald: CRC Crit. Rev. Toxicol. 11, 85 (1983).

2. C.E. Castro, R.S. Wade, and N.O. Besler: Environ. Tox. Chem. 8, 13 (1985).

3. M.S.P. Logan, L.M. Newman, C.A. Schanke and L.P. Wackett: Biodegradation 4, 39 (1993).

4. M.D. Paulsen and R.L. Ornstein: J. Comp. Aided Molec. Design. (1994), in press.

5. A.T. Hagler: in The Peptides, 7, 213, V.J. Hruby and J. Meienhofer, Ed., Academic Press, New York (1985). P. Dauber-Osguthorpe, V.A. Roberts, D.J. Wolff, M. Genest, A.T. Hagler: Proteins :Struct .Funct. Genetics 4,31 (1988).

6. Gaussian 92, Revision-D.2, Gaussian, Inc., Pittsburgh PA. M.J. Frisch, G.W. Trucks, M. Head-Gordon, P.M.W. Gill, M.W. Wong, J.B. Foresman, B.G Johnson, H.B., Schlegel, M.A. Robb, E.S. Replogle, R. Gomperts, J.L. Andres, K. Raghavachari, J.S. Binkley, C. Gonzalez, R.L. Martin, D.J. Fox, D.J. Defrees, J. Baker, J.J.P. Stewart and J.A. Pople (1992).

7. T.L. Poulos, B.C. Finzel and A.J. Howard: J. Mol. Biol. 195, 687 (1987).

8. C.M. Breneman and K.B. Wiberg: J. Comp. Chem. 11, 361 (1990).

9. L.E. Chirlian and M.M. Francl: J. Comp. Chem. 8, 894 (1987).

10. U.C. Singh and P.A. Kollman: J. Comp. Chem. 5,129 (1984).

11. P.J. Hay and W.R. Wadt: J. Chem. Phys. 82, 270 (1985). P.J. Hay and W.R. Wadt: J. Chem. Phys. 82, 284 (1985). P.J. Hay and W.R. Wadt: J. Chem. Phys. 82, 299 (1985).

12. T.H. Dunning and P.J. Hay: Plenum, New York (1976).

13. A.J.H. Wachter: J. Chem. Phys. 52, 1033 (1970).

14. H.A. Carlson, T.B. Nguyen, O. Modesto and W.L. Jorgensen: J. Comp. Chem. 14, 1240 (1993).

15. S.J. Weiner, P.A. Kollman, D.T. Nguyen and D.A. Case: J. Comp. Chem. 7, 230 (1986).

16. J.P. Jones, W.F. Trager and T.J. Carlson: J. Am. Chem. Soc. 115, 381 (1993).

17. A.E. Reed and F.J. Weinhold: QCPE Bull. 5, 141 (1985). A.E. Reed, R.B. Weinstock and F.J. Weinhold: J. Chem. Phys. 83, 735 (1985).

18. M.A. Lopez and P.A. Kollman: J. Am. Chem. Soc. 111, 6212 (1989).

19. K. Kuczera, J. Kuriyan and M. Karplus: J. Mol. Biol. 213, 351 (1990).

20. M.C. Zerner, M. Gouterman and H. Kobayashi: Theor. Chin.. Acta 6, 363 (1966).

21. B.R. Brooks, R.E. Bruccoleri, B.D. Olafson, D.J. States, S. Swaminathan and M. Karplus: J. Comp. Chem. 4, 187 (1983).

22. J. R. Collins, D. L. Camper and G. H. Loew: J. Am. Chem. Soc. 113, 2736 (1991).

23. W.D. Edwards, B. Weiner and M.C. Zemer: J. Am. Chem. Soc. 108, 2196 (1986). W.D. Edwards and M.C. Zerner: Theor. Chim. Acta 72, 347 (1987). J. Ridley and M.C. Zerner: Theor. Chim. Acta 32, 111 (1973). J. Ridley and M.C. Zerner: Theor. Chim. Acta 42, 223 (1976). A.D. Bacon and M.C. Zerner: Theor. Chim. Acta 53, 21 (1979). M.C. Zerner, G.H. Loew, R.C. Kirchner and U.T. Mueller-Westerhoff: J. Am Chem. Soc. 102, 589 (1980). 
24. P.R. Ortiz de Montellano, J.A. Fruetel, J.R. Collins, D.L. Camper and G.H. Loew: J. Am. Chem. Soc. 113, 3195 (1991).

25. M.D. Paulsen, D. Filipovic, S.G. Sligar and R.L. Ornstein: Protein Science 2,357 (1993).

26. M.D. Paulsen and R.L. Ornstein: Protein Engineering 6,359 (1993).

27. S. Yamamoto and H. Kashiwagi: Chem. Phys. Lett. 145, 111 (1988). S. Yamamoto, J. Teraoka and H. Kashiwagi: J. Chem. Phys. 88, 303 (1988).

28. S. Yamamoto and K. Kashiwagi: Chem. Phys. Lett. 205, 306 (1993).

29. D. Harris and G.H. Loew: J. Am. Chem. Soc. 115, 5799 (1993). 

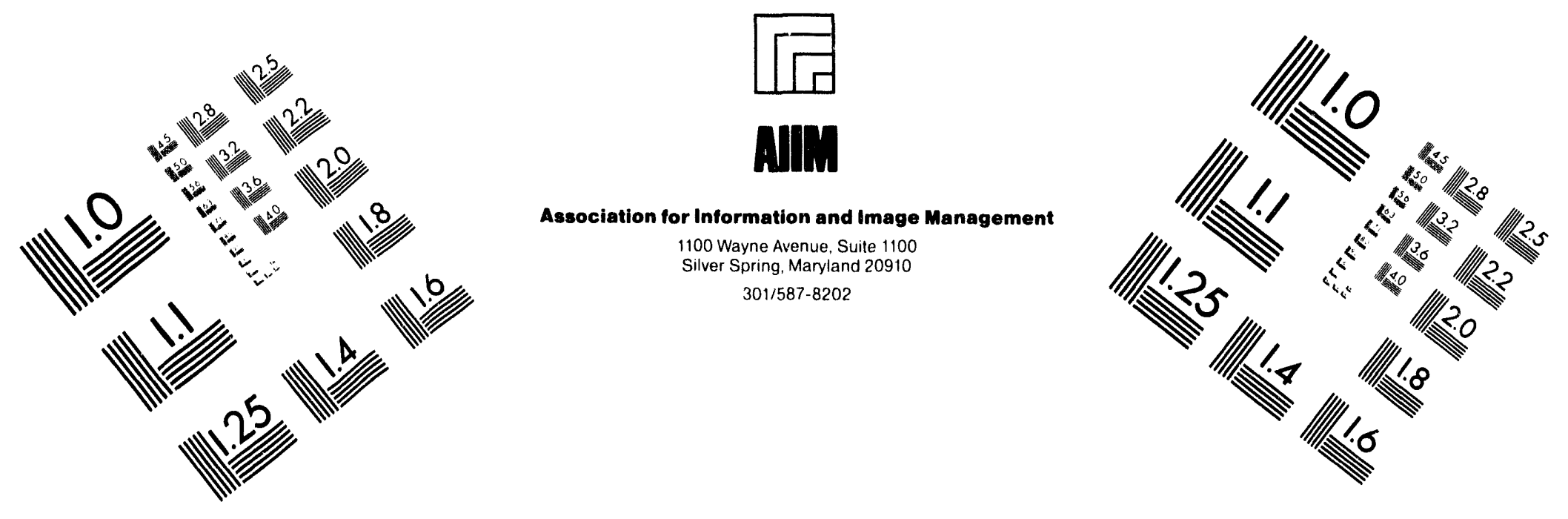

\section{Centimeter}

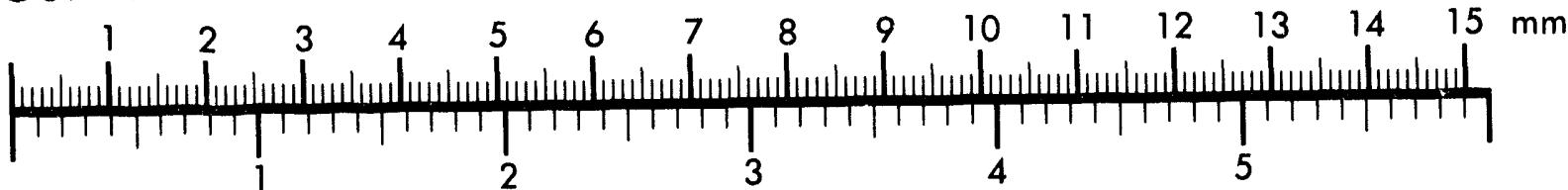
Inches
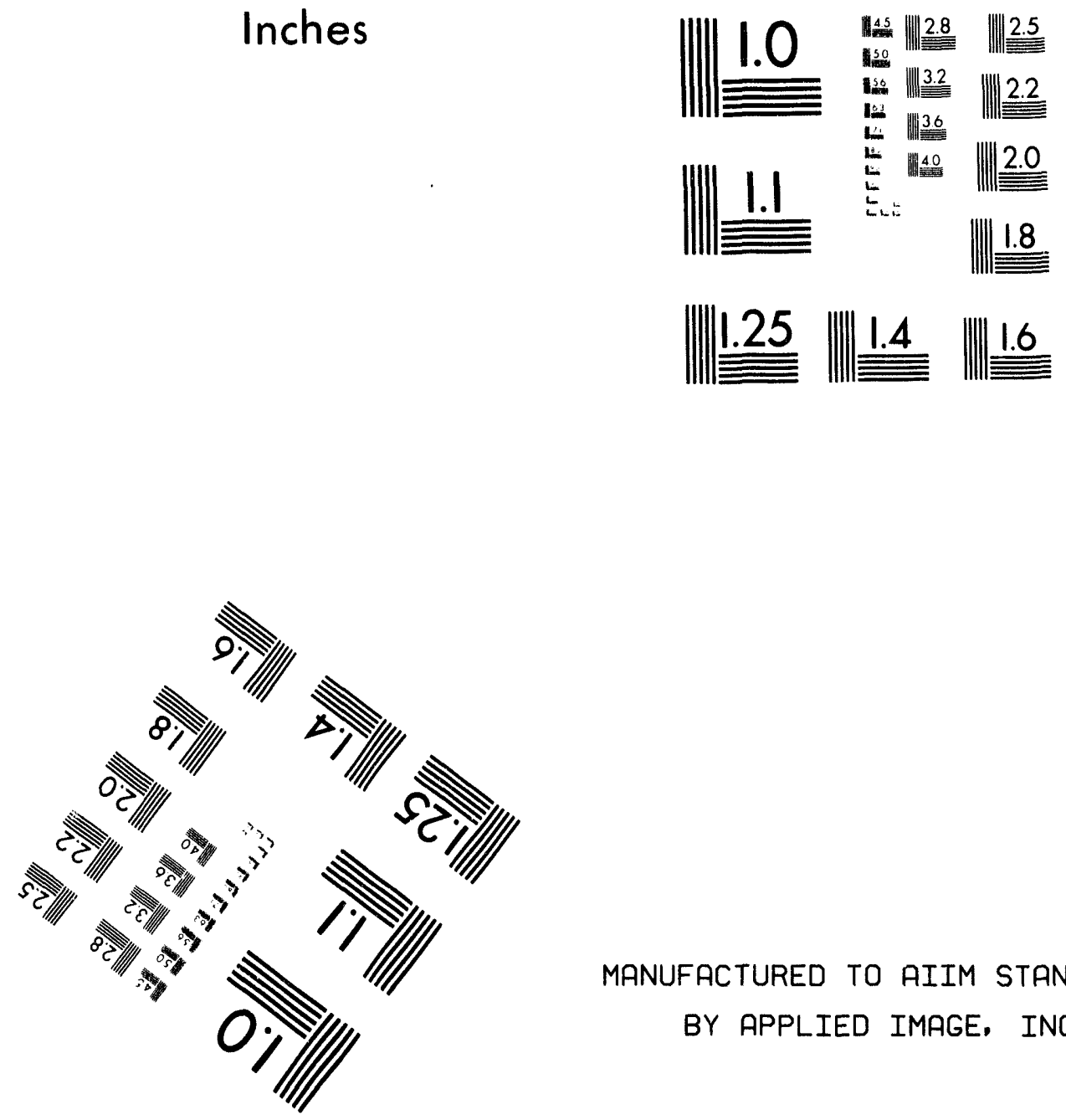

MANUFACTURED TO AIIM STANDARTS

BY APPLIED IMAGE, INC.

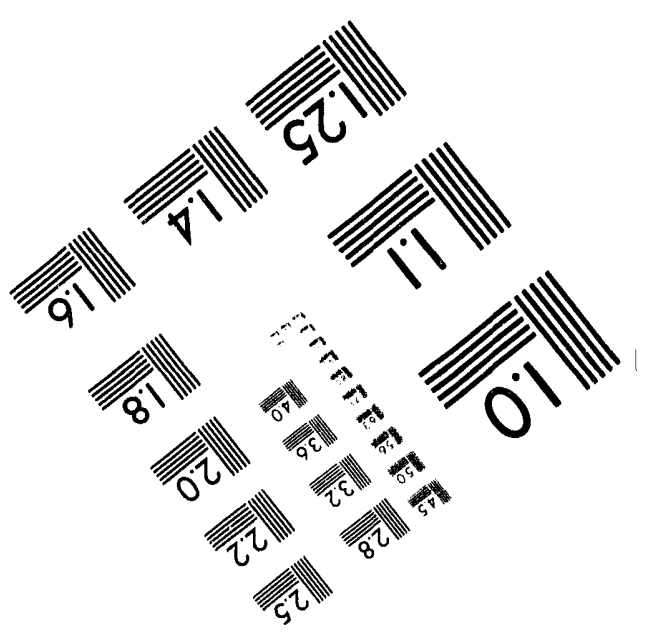



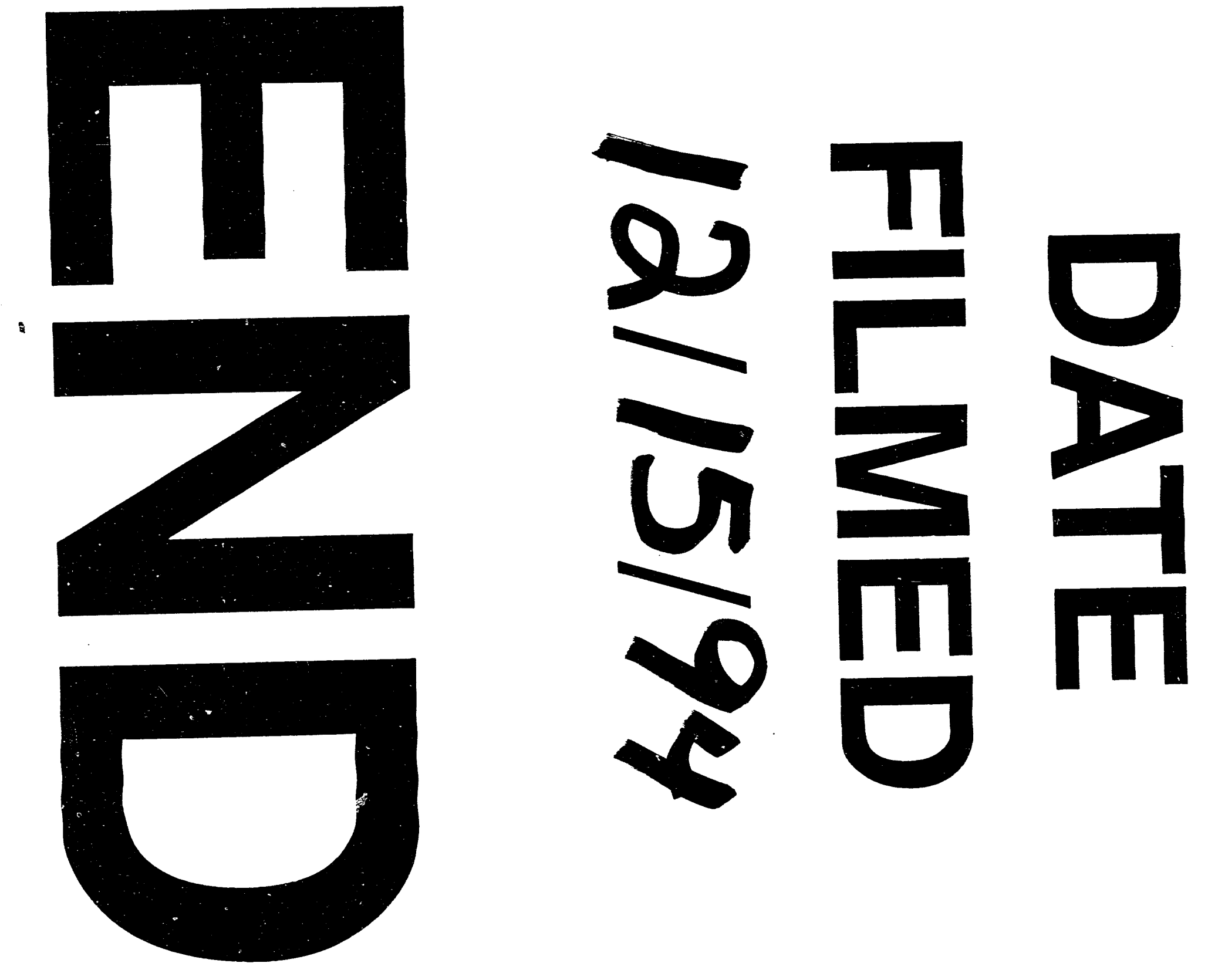